\title{
A história do ensino em administração: contribuições teórico-metodológicas e uma proposta de agenda de pesquisa*
}

\author{
Tânia Fischer** \\ Claudiani Waiandt*** \\ Renata Lara Fonseca****
}

Sumário: 1. Introdução; 2 . A história do ensino de administração: um subcampo de pesquisa; 3. O subcampo história do ensino de administração: níveis e possibilidades; 4. Contribuições metodológicas da historiografia da educação à história do ensino de administração; 5. Considerações finais.

Summary: 1. Introduction; 2 . The history of business administration education: a research subfield; 3 . The history of the business administration education subfield: levels and opportunities; 4 . Methodological contributions of the historiography of education to the history of business administration education; 5. Final considerations.

Palavras-chave: ensino; história do ensino; conhecimento; administração; metodologia.

\footnotetext{
* Artigo recebido em nov. 2010 e aceito em mar. 2011.

** Professora titular da Escola de Administração da Universidade Federal da Bahia (EAUFBA). Coordenadora do Centro Interdisciplinar de Desenvolvimento e Gestão Social (Ciags) da EAUFBA. Pesquisadora DTI 1A do CNPq. Vice-presidente do Fórum Nacional de Mestrados Profissionais. Membro do Comitê Diretor do Programa Pró-Administração da Capes. Membro do Conselho da Fundação Banco do Brasil e Conselho de Responsabilidade Social da Federação das Indústrias da Bahia. Doutora em administração pela Universidade de São Paulo (USP). Endereço: Escola de Administração da UFBA, av. Reitor Miguel Calmon, s/n, 3o andar — Vale do Canela — CEP 40903-170, Salvador, BA, Brasil. E-mail: taniafischer@ciags.org.br.

*** Doutora em administração pela Universidade Federal da Bahia (UFBA). Professora e pesquisadora da Escola de Administração da UFBA. Coordenadora adjunta do Mestrado Multidisciplinar e Profissionalizante de Desenvolvimento e Gestão Social do Ciags da EAUFBA. Endereço: rua General Labatut, 288, ap. 1704 - Barris - CEP 40070-100, Salvador, BA, Brasil. E-mail: cwaiandt@ig.com.br.

*:*** Pesquisadora do Ciags da EAUFBA. Graduada em secretariado executivo pela UFBA. Endereço: rua Nossa Senhora de Brotas, 35, ap. 801 - Brotas - CEP 40283-170, Salvador, BA, Brasil. E-mail: renatalarafonseca@gmail.com.
} 
KEY WORDS: teaching; the history of education; knowledge; business administration; methodology.

O debate sobre a importância do campo da história na área de administração ficou restrito, principalmente, aos estudos ligados à história dos negócios ou empresariais, à história da gestão e à história organizacional (Costa, Barros e Martins, 2009). No sentido de ampliá-lo, este artigo apresenta a historiografia do ensino e propõe quatro níveis de pesquisa sobre a história do ensino de administração: a) a vida dos mestres (professores) que construíram campos temáticos, formas de ensinar e instituições; b) os legados de ensino dos programas; c) a história das disciplinas escolares; e, d) a história das instituições de ensino. Além disso, revela as possibilidades teóricometodológicas da historiografia da educação para, desta forma, propor uma agenda de ações no sentido de institucionalizar o subcampo de história do ensino de administração no campo da história da administração. Finalmente, conclui-se com a proposta de se ensinar a história do ensino de administração no Brasil, disciplina que é praticamente inexistente nos currículos da área, mais particularmente, esse tema pode ser um componente curricular de disciplinas ou atividades que se propõem a formar mestres e doutores.

The history of business administration education: theoretical-methodological contributions and a proposed research agenda

Debate about the importance of the field of history within the area of business administration has principally been restricted to studies about business or company history, the history of management and organizational history (Costa, Barros \& Martins, 2009). In order to broaden this debate, this article presents the historiography of its teaching and proposes four research levels for the history of business administration education: a) the lives of the masters (teachers) who have constructed thematic fields, teaching modes and institutions; b) the educational legacy of these programs; c) the history of school subjects; and d) the history of institutions of education. Furthermore, it uncovers theoretical-methodological possibilities for the historiography of education and thus proposes an activity agenda towards the institutionalization of the subfield of the history of business administration education within the field of the history of business administration. It concludes with a proposal to teach the history of business administration education in Brazil - a subject practically nonexistent within the area's curricula — and specifically proposes that this topic should become a curricular component within the subjects or activities that constitute master's and doctorate education.

\section{Introdução}

Este artigo contribui para o debate sobre o ensino de administração, mais especificamente, pretende compreender a perspectiva histórica nesta área. 
Assim, apresenta quatro níveis de pesquisa sobre a história do ensino de administração e revela as possibilidades teórico-metodológicas da historiografia da educação para, desta forma, propor uma agenda de ações no sentido de institucionalizar o subcampo de história do ensino de administração no campo da história da administração.

O debate sobre a importância do campo da história na área de administração ficou restrito nos últimos anos, principalmente, aos estudos ligados à história dos negócios ou empresariais (business history), à história da gestão (management history) e à história organizacional (organizational history), conforme artigo publicado por Costa, Barros e Martins (2009). Nesse trabalho, os autores apresentaram três abordagens do pensar administrativo, relacionando-as com a discussão paradigmática da história, resgatando a ideia da utilização da metodologia da nova história para o estudo da administração. Esse movimento de resgate na área de administração, no Brasil, iniciou-se nas últimas décadas com os trabalhos de Curado (2001b), Martins (1989, 1990), Sauerbronn e Faria (2006), Vizeu (2007) e Pieranti (2008).

Apesar desse resgate, verifica-se que há uma lacuna quando se enfatiza o campo de pesquisa e ensino de administração e se busca compreender a trajetória dessa área evidenciada por sua evolução, pela história das instituições - associações como Associação Nacional de Pós-graduação e Pesquisa em Administração (Anpad), escolas e programas - e pelo estudo de vida de professores, entre outros temas como os legados de ensino traduzidos em currículos e programas. Nesse sentido, uma série de trabalhos contribui direta e indiretamente para a construção desse campo de pesquisa como, por exemplo, Matta (1979), Covre (1981), Motta (1983), Keinert (1986, 1994), Martins (1989, 1990), Oliveira (1993), Curado (2001b), Skora e Mendes (2001), Silva, Teixeira e Magalhães (2005), Fachin (2006), Nicolini (2002, 2007), Godoy, Moreira e Takei (2002), Fischer (1984, 2010), Coelho (2006), Waiandt (2009) e Coelho e Nicolini (2010).

Esses trabalhos, frutos de projetos de pesquisas acadêmicas ou de trabalhos de cursos de pós-graduação, apresentam o desenvolvimento da administração enquanto matéria de ensino e campo do conhecimento, além de registrarem as contribuições de instituições e sujeitos, especialmente, professores, numa perspectiva histórica.

A historiografia ou história da educação possibilita novos entendimentos da ação educativa. Conforme Saviani (2007), o campo da história da educação começou a se configurar no interior do campo da educação brasileira a 
partir da década de 1930, mas foi a partir de 1984, com a criação de um Grupo de Trabalho (GT) na Associação Nacional de Pós-graduação e Pesquisa em Educação (Anped), que as pesquisas de historiografia da educação ganharam impulso. Assim, foram surgindo em diferentes instituições e em diversos locais grupos de pesquisa em história da educação que difundiram suas pesquisas a partir da realização de eventos, culminando, em 1999, com a fundação da Sociedade Brasileira de História da Educação (SBHE). Esse campo é considerado em processo de consolidação (Saviani, 2007; Saviani, Lombardi e Sanfelice, 2006; Morais, Portes e Arruda, 2006), dado que atualizou nos anos 2000 o debate desenvolvido ao longo do século XX que incorporou as transformações do campo da história.

Assim, propõe-se a seguinte questão: que agenda de ações estratégicas pode estabelecer um espaço teórico-metodológico que permita reconstruir os percursos da história do ensino de administração, no Brasil, de modo a compreender o passado e o presente e prospectar o futuro?

A construção de um espaço referencial de história do ensino de administração deve considerar o desenvolvimento de uma comunidade de interesses e a institucionalização do subcampo em organizações representativas na comunidade acadêmica e nos veículos de profusão e divulgação. Desta forma, realizou-se uma pesquisa descritivo-explicativa (Vergara, 1997) por meio de levantamento bibliográfico na área de administração e educação, procurando subsídios para apresentar uma agenda de pesquisa.

O artigo foi subdividido em quatro seções. Após essa introdução, o segundo tópico apresenta o subcampo de pesquisa da história do ensino em administração, o terceiro propõe quatro níveis de pesquisa sobre o tema e exemplifica trabalhos realizados, o quarto tópico apresenta contribuições da metodologia da historiografia da educação e o quinto traz, nas considerações finais, a proposta de uma agenda.

\section{A história do ensino de administração: um subcampo de pesquisa}

A história do ensino em administração (HEA) é um subcampo de pesquisa por sua natureza interdisciplinar, pois recebe diretamente influência de três áreas de conhecimento: educação, administração e história (figura 1), conforme categorização de áreas do conhecimento do Conselho Nacional de Desenvolvimento Científico e Tecnológico (CNPq, 2010). 
Disciplinas constitutivas do subcampo de HEA

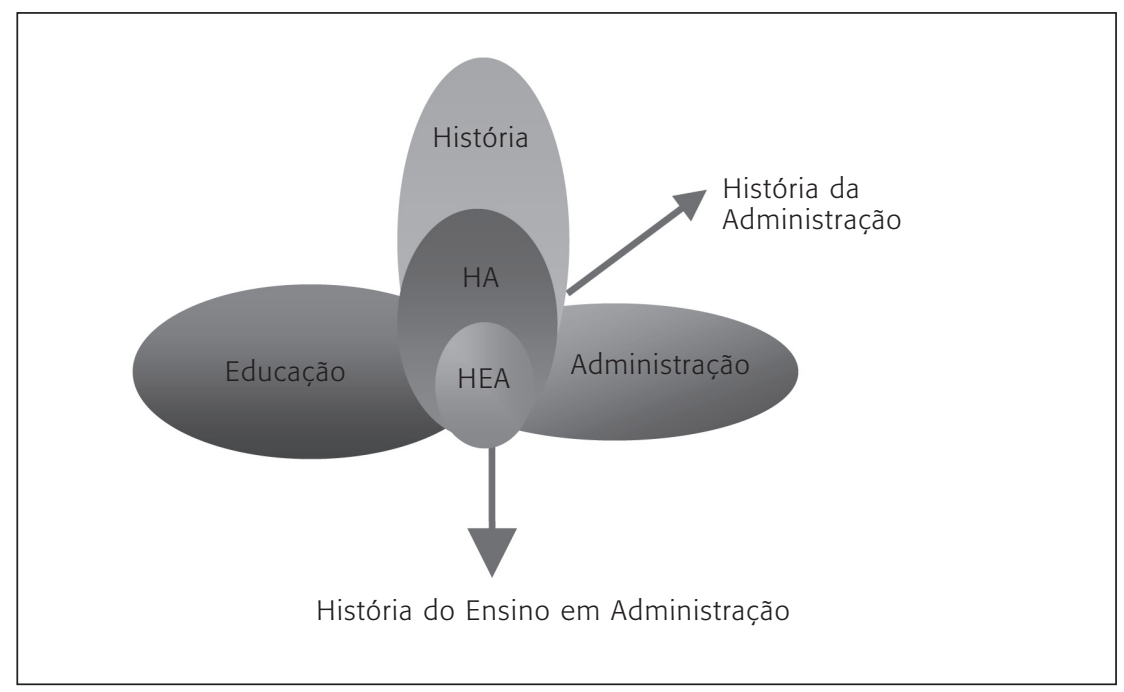

Fonte: elaboração própria.

Percebe-se, conforme figura 1, que a associação da "administração e história" constrói o campo da história da administração, já discutida por Costa, Barros e Martins (2009). Se relacionarmos a história da administração ao ensino, cria-se um distinto subcampo de confluência de três áreas (história, educação e administração).

Esse subcampo é interdisciplinar na medida em que a confluência de três grandes áreas disciplinares possibilita o recorte de temas integradores (por exemplo, a história dos programas de pós-graduação em administração no Brasil), o uso de metodologias e recursos de pesquisa validados nas três áreas, permitindo triangulações que refinam as possibilidades de análise e o contato entre três comunidades de pesquisadores (educadores, administradores e historiadores) que pode gerar interações entre repertórios e práticas de pesquisa.

A história tem uma concepção cumulativa do tempo, por isso, o presente tem melhor condição de entender o passado do que este mesmo passado teve condições de entender a si mesmo. Nesse sentido, as ações humanas acabam ressignificando as experiências vividas e, ao mesmo tempo, imprimem determinados significados aos eventos, que nem sempre são apreendidos pelos quadros referenciais de nossa cultura (Decca, 1998). 
Essa concepção de estudar o passado para compreender o presente foi sendo construída desde o movimento da "Escola dos Annales" (Burke, 1997), na França, que provocou uma renovação teórico-metodológica no campo da história por meio da história-problema. Além da pluralidade dos níveis da temporalidade e da legitimação da história-problema, o movimento, que culminou na história nova (Le Goff, 1993), enfatizou a utilização de outras fontes que não as documentais, ampliando as estratégias de pesquisas no campo da história e valorizando e resgatando temas e o diálogo com diferentes áreas científicas.

No Brasil, a partir do fim da década de 1970, esse movimento trouxe transformações significativas nos diferentes campos da pesquisa histórica:

o estudo de temas contemporâneos foi incorporado, a análise qualitativa foi revalorizada, a importância das experiências individuais foi resgatada, ou seja, o interesse foi deslocado das estruturas para as redes, dos sistemas de posições para as situações vividas, das normas coletivas para as situações singulares (Ferreira, 2003:10).

A renovação da historiografia, proporcionada pela história nova, trouxe também mudanças teórico-metodológicas importantes para a história da educação, enfatizando novos temas de pesquisa, fontes não escritas e distintos métodos.

A histografia da educação é um campo de estudo que tem por objeto de investigação as produções históricas que estudam a educação. Apesar de ser um campo recente na educação, a historiografia da educação reproduziu características da produção historiográfica, "com trabalhos em que a produção no campo da história educacional é de caráter descritivo, com ênfase nos aspectos formais da produção" (Lombardi, 2004:153).

Desta forma, também o campo da historiografia da educação passou por transformações. A revalorização da análise qualitativa e das situações singulares ressaltou fontes como, por exemplo, material lírico e cerâmico, documentos escritos além dos ditos oficiais, testemunhos orais, produções iconográficas, audiovisuais, eletrônicas etc., que, consequentemente, ressaltaram novas formas de metodologias de pesquisa como biografia, autobiografia, história de vida, história oral etc., proporcionando uma valorização do sujeito, que voltou a ser ator de sua própria história.

Em menor escala, o fenômeno historiográfico tem profundas implicações para a pesquisa em administração e, especialmente, para seu ensino, pois 
o objeto de investigação da história do ensino de administração — o ensino de administração - é estudado a partir de métodos e teorias próprios à pesquisa e investigação histórica educacional; e do ponto de vista do enfoque, dado que pesquisar em história do ensino de administração é investigar o objeto ensino de administração da perspectiva histórica.

Num movimento interdisciplinar, a história do ensino em administração resgata material teórico-metodológico na produção da historiografia da educação para desvendar as trajetórias de ensino, bem como descortinar a contribuição da história do ensino na construção da área da administração.

Esses métodos de pesquisa serão discutidos após o relato de temas e trabalhos relacionados ao subcampo de pesquisa história do ensino de administração.

\section{O subcampo história do ensino de administração: níveis e possibilidades}

O ensino de administração recortado a partir da historiografia da educação pode ser classificado em quatro níveis para pesquisa (Fischer, 2010), a saber:

1) a vida dos mestres (professores) que construíram, a partir de seu trabalho docente, campos temáticos, formas de ensinar, organizações e instituições;

2) os legados de ensino, ou a história dos currículos, dos programas e modos de ensinar e aprender;

3) a história das disciplinas ou a história da evolução do pensamento na área de administração; e,

4) a história das instituições de ensino de administração no Brasil.

Todavia, qualquer que seja o nível escolhido, os outros três podem estar contemplados enquanto perspectiva de abordagem. "Ou seja, há uma necessária imbricação destes níveis de análise e convergências inevitáveis entre mestres, desenhos de ensino, instituições de ensino e conteúdos a serem ensinados" (Fischer, 2010:217).

Com o objetivo de compreender esses níveis, registram-se a seguir possibilidades de temas para a pesquisa e exemplos de trabalhos realizados sobre cada nível de análise. 


\subsection{A vida de mestres referenciais}

A vida dos professores e seus efeitos na construção de instituições e na arquitetura do conhecimento traduzidas em matérias, disciplinas e desenhos curriculares tornaram-se objeto de investigação na área de educação na década de 1980, com a publicação de estudos sobre "a vida dos professores, as carreiras, os percursos profissionais, as biografias e autobiografias docentes ou o desenvolvimento profissional dos professores" (Nóvoa, 2000:13).

O professor, como sujeito coletivo, é a um só tempo produto e protagonista do processo de ensino. Quando se trabalha com relatos e histórias de vida dos professores, pode-se fazer emergir discussões sobre temas e questões que vislumbram além da história pessoal e profissional do professor, como fatos da história relacionados a dimensões mais amplas da vida social, política e econômica.

Nesse sentido, ao estudar a vida do professor na administração, podese compreender como se deu a consolidação de recortes de ensino nos cursos de administração, como são construídos seus desenhos curriculares, qual a contribuição de instituições de ensino e de fomento/regulação no processo de construção da administração como matéria de ensino ou como se constroem redes de pesquisas sobre temas de administração ao longo do país.

Além disso, as pesquisas sobre a vida de professores marcam o retorno e a centralidade do sujeito no movimento que discute o ofício do professor (Fischer, 2010). Qual é a função do professor de administração? Como se dá o processo de formação desse professor na área de administração? Qual é a importância da formação do professor na área de administração? Quais as práticas pedagógicas utilizadas pelos professores de administração? Essas são questões que podem ser compreendidas a partir da história da vida dos professores.

Na área de administração, ao analisar a história de vida de Alberto Guerreiro Ramos, Fischer (2010) sinaliza as possibilidades da pesquisa sobre a vida e a obra de professores, mostrando dois momentos da vida de Guerreiro Ramos: sua formação e, posteriormente, sua vida profissional, exercendo papéis distintos, quando deixou diversos legados, como técnico, militante, político, cientista social e docente.

Em síntese, a trajetória dos mestres "contribui para se compreender o contexto de ensino do presente e os movimentos de convergência e dissonância de campos estruturantes das áreas da administração" (Fischer, 2010:209). Mestres, como Alberto Guerreiro Ramos, que elaboraram teorias inspiradoras e a construção de um espaço de ensino para si e para outros 
com seu conhecimento e sua capacidade relacional, também construíram instituições e programas de ensino e ainda são recordados por discípulos em atividade acadêmica.

A pesquisa da vida dos professores pode se valer de uma série de métodos. Todavia, ressaltam-se os métodos enfatizados após a renovação da historiografia, como a história de vida, a biografia, a autobiografia, além de fontes de coleta de dados, como os depoimentos orais, as memórias, acervos orais (Nóvoa, 2000), que serão discutidos mais adiante. Embora com características próprias, esses métodos e fontes possibilitam relacionar as experiências de vida desses professores com sua práxis pedagógica, num constante processo de ensino e aprendizagem.

Para Thomson, Frisch e Hamilton (2002:75), essas novas metodologias foram enfatizadas no esforço de recuperar a experiência e os pontos de vista daqueles que normalmente permanecem invisíveis na documentação histórica convencional e de considerar seriamente essas fontes como evidência.

\subsection{Os legados de ensino}

O nível "legados de ensino" é formado pela história do currículo, dos programas e dos modos de ensinar e aprender. Esse nível de pesquisa sobre a história do ensino de administração tem recebido interesse por parte dos pesquisadores na área (Covre, 1981; Curado, 2001b; Nicolini, 2007; Waiandt, 2009).

A perspectiva construcionista da história do currículo (Bittencourt, 2003; Rocha, 2003; Goodson, 1992, 1995) emergiu por volta da década de 1970, quando a sociologia do conhecimento precipitara o advento de uma nova sociologia da educação, na Inglaterra, e a sociologia do currículo, na América do Norte (Pessanha, Daniel e Menegazzo, 2004). Essa perspectiva busca desvelar a arbitrariedade dos processos de seleção e de organização do conhecimento educacional e, mais particularmente, do conhecimento escolar (Rocha, 2003), tentando explicar o conhecimento não como algo que se transmite aos alunos de um modo acrítico, mas enquanto conhecimento considerado socialmente válido por determinado grupo social, em um período de tempo.

O objetivo central da história do currículo não se restringe simplesmente à descrição de como se organizava o conhecimento escolar no passado com a finalidade de comparar com a situação atual. É importante verificar como foi efetivado o processo de seleção e organização do conhecimento ao longo do tempo (com conflitos e lutas entre diferentes tradições e concepções sociais), como são atribuídos diferentes significados ao longo do tempo às mesmas pa- 
lavras e como os processos informais e interativos subvertem e transformam o que é dito "legal" (Silva, 2007).

Em suma, uma das principais características das pesquisas direcionadas para a história do currículo é o caráter histórico-social e, nesse sentido, suas pesquisas enfatizam o estudo de fontes orais somado a documentos para compreender a construção do conhecimento.

Na administração, o estudo de Covre (1981) faz uma análise histórica sobre a trajetória dos cursos de administração a partir da leitura da legislação e dos fatos políticos. Para a autora, o processo de desenvolvimento dos cursos foi marcado por dois momentos históricos distintos. O primeiro, pelo governo de Getúlio Vargas, representativo do projeto "autônomo" de caráter nacionalista. O segundo, pelo governo de Juscelino Kubitschek, evidenciado pelo projeto de desenvolvimento associado, caracterizado pelo tipo de abertura econômica de caráter internacionalista. Este último apresentou-se como um ensaio do modelo de desenvolvimento adotado após 1946.

Um trabalho que colabora nesse nível de pesquisa é a tese de doutorado de Coelho (2006), que analisa o ensino de graduação em administração pública no Brasil no tocante à sua evolução histórica e à experiência recente. Assim, apresenta uma meticulosa sistematização da trajetória do ensino superior no país, desde sua gênese até meados dos anos 1990, relaciona a experiência brasileira da última década e se desdobra em duas frentes: 1) o exame das circunstâncias em que esse ensino se expande e a contextualização de sua oferta, e 2) a categorização, a partir de evidências empíricas, dos principais obstáculos com os quais esse ensino se depara.

Outro trabalho é a dissertação de Silva (2007), que mostrou a trajetória curricular de cursos de graduação em ensino de administração em Salvador, levando em consideração as alterações ocorridas na legislação por meio do examine dos dispositivos legais que regulam os cursos de graduação, desde o ano de 1966 até 2005. A pesquisa foi feita por meio de estudo de caso (múltiplo) em três instituições de ensino: Universidade Federal da Bahia, Universidade Católica do Salvador e Faculdade Ruy Barbosa; com recursos de pesquisa história para abordar o tema em questão. A autora verificou que as instituições estudadas se distinguem em sua trajetória curricular, devido a sua organização administrativa; o fluxograma é o desenho curricular típico dessas IES; e as IES, de modo geral, atendem, preferencialmente, aos aspectos legais, em detrimento dos aspectos metodológicos, na elaboração e construção da estrutura curricular.

Além da história do currículo, outro legado de ensino que perpassa esse nível são os modos de ensinar e aprender. O professor, ao percorrer sua vida 
acadêmica, perpetua maneiras de ensinar e aprender que ficam marcadas na memória de seus estudantes.

Nicolini (2007), em sua tese de doutorado, analisa a aprendizagem dos funcionários públicos por meio de quatro dimensões: 1) o surgimento e evolução da formação em administração pública no país; 2) as escolas de governo, lugares propícios à aprendizagem, influentes para a administração pública do país, inclinados à discussão de novas soluções e críticos na identificação, análise e apropriação das experiências verificadas em outras realidades; e, 3) os cursos de formação inicial, espaços para o primeiro contato com a função escolhida e seus desafios, saberes necessários e ferramentas disponíveis; e, 4) a inserção no ambiente de trabalho, decisiva para o processo de aprendizagem social dos funcionários novatos por intermédio das comunidades de prática.

Outro trabalho nesse sentido foi realizado por Silva, Teixeira e Magalhães (2005), que debateram o ensino da administração diante das experiências de gestão na economia solidária. As autoras registraram o caso da Escola de Administração da Universidade Federal da Bahia (EAUFBA), que vivenciou algumas experiências de ensino, pesquisa e extensão na gestão de empreendimentos solidários. Todavia, registraram que ainda não existem estudos e reflexão sobre gestão de empreendimentos solidários na instituição pesquisada, apesar da abertura dos professores e interesse dos alunos ao tema, algo já constatado em pesquisa anterior. A maioria das disciplinas no curso de administração está voltada para o viés empresarial, algumas ainda tratam sobre administração pública, porém poucas se dedicam a temas como economia solidária, terceiro setor ou cooperativismo. Não obstante, a carência de trabalhos e pesquisas que contemplem a gestão dos empreendimentos solidários não é um fato isolado na Escola de Administração da UFBA.

\subsection{A história das disciplinas e a história da evolução do pensamento na área de administração}

Uma das áreas de estudos que mais têm contribuído para a história dos currículos é a chamada história das disciplinas escolares (Chervel, 1990). As pesquisas desenvolvidas nesse campo

objetivam explicar as transformações ocorridas em uma disciplina ao longo de sua trajetória. Assim, é possível identificar os fatores mais diretamente ligados às mudanças de conteúdo e aos métodos de ensino, o que indubitavelmente 
possibilita maior articulação de propostas mais consistentes de mudanças curriculares (Rocha, 2003:49).

Além disso, as pesquisas nesse nível buscam explicar o porquê de um conhecimento ser ensinado nas escolas em determinado momento e local, e a razão de ele ser conservado, excluído ou alterado ao longo do tempo; e ainda verificar como os rumos de uma disciplina são afetados por debates e disputas entre os subgrupos que a compõem, bem como as influências decorrentes de aspectos da política educacional e da sociedade mais ampla sobre essas disputas. Ainda segundo Rocha (2003:50), pode-se perceber tais conflitos por meio da "análise de objetivos, documentos, encontros de associações de professores, estudantes, pesquisadores, programas oficiais, conferências, pesquisas, relatórios, leis, decretos, pareceres e políticas educacionais que, de forma mais explícita ou quase despercebidamente, os refletem".

Na área de administração, esse nível de análise tem ganhado adeptos como Fischer (1984), Skora e Mendes (2001), Curado (2001a), Godoy, Moreira e Takei (2002) e Waiandt (2009).

Em sua tese de doutorado, Fischer (1984) analisou a trajetória brasileira do ensino de graduação em administração pública por meio da análise do Programa de Ensino de Administração Pública e de Empresas (PBA-1) do governo federal, implantado nos anos 1960. Com esse trabalho, a autora mostrou as possibilidades da pesquisa histórica para o ensino de administração.

Na década de 2000, um estudo realizado por Skora e Mendes (2001) buscou discutir a disciplina Teoria Geral da Administração à luz da implementação de diretrizes curriculares de 2001. Nesse sentido, os autores apresentaram um histórico da formação dos cursos de administração no Brasil e da proposta de diretrizes curriculares para o curso. Os autores confirmam a importância da disciplina TGA por meio de uma pesquisa exploratória com 290 alunos de duas faculdades de administração em Curitiba, mas verificam que os conteúdos são inadequados já que $40 \%$ das aulas são dedicadas a um autor e não há complementação de obras atualizadas. Além disso, verificaram que as aulas estão basicamente utilizando técnicas expositivas e estudos de casos que não incentivam a participação na construção do conhecimento. Ressaltam ainda o problema da utilização dos manuais estrangeiros e, finalmente, propõem diretrizes para a organização da disciplina.

Contribuindo para a história da evolução do pensamento na área de administração, Curado (2001a) desenvolveu sua tese de doutorado com objetivo de resgatar o desenvolvimento da administração paulista, segundo três categorias de saber administrativo: saber prático, saber tecnológico e saber plu- 
ral. Nessa pesquisa, além de documentos, a autora entrevistou professores que, além da atividade de docência, estiveram envolvidos, ao longo de sua carreira, com consultoria e pesquisa em administração. Para Curado (2001a:160-161),

No caso da administração, defendemos que existem três tipos de saberes administrativos, que ocorrem em três momentos históricos diferentes. Em países desenvolvidos, o saber prático, predominou na realidade empresarial até a virada do século XIX. O saber tecnológico começou a ser implantado nas primeiras décadas do século XX e dominou a realidade administrativa, tanto empresarial quanto acadêmica, até a década de 70. A partir deste momento, ocorreu um questionamento do modelo único proposto pelo saber tecnológico e o consequente estabelecimento do saber plural. Enquanto o campo de conhecimento da administração, de uma forma geral, seguiu essa cronologia, em São Paulo, esses saberes ocorreram em outros períodos. O saber prático predominou na realidade paulista até a década de 50 . O saber tecnológico desenvolveu-se a partir de 1955, porém a sua consolidação só ocorre na década de 70. O questionamento do saber tecnológico e a adoção do saber plural só ocorreram na década de 90 .

Outro trabalho que ressaltou a história das disciplinas foi desenvolvido por Godoy, Moreira e Takei (2002), que avaliaram os planos de ensino de disciplinas ligadas às teorias da administração, ministradas em cursos superiores de administração de empresas no município de São Paulo. Os autores verificaram algumas omissões de itens importantes dos programas, falta de padronização, alguns casos de desatualização do conteúdo programático, excesso de itens de conteúdo e confusão na elaboração de ementas. No intuito de colaborar com o tema, eles elaboraram uma sugestão de conteúdo programático e ementa.

Mais recentemente, a tese de doutorado de Waiandt (2009) resgatou a história das disciplinas escolares e a história do currículo, com o objetivo de compreender como se configura e se ensina o campo dos estudos organizacionais (EO) nos programas de pós-graduação stricto sensu no Brasil. Nessa pesquisa, a autora verificou que o campo dos EO acaba sendo um eixo estruturador do currículo dos programas estudados (Eaesp/FGV/SP, Ebape/FGV/RJ, UFBA, UFMG, UFPE, UFPR, UFRGS, UFSC e UnB), mas é ensinado de maneira repetitiva e não estruturada nos dois níveis de ensino (mestrado e doutorado). Além disso, verificou que os conteúdos selecionados para o ensino passam por ampliações, inclusões e exclusões de acordo com as mudanças no corpo docente da instituição ou com a interação dos docentes dos programas; são, 
predominantemente, estrangeiros e influenciados pelas relações de poder ao longo do tempo. A pesquisa da autora foi realizada a partir de documentos das instituições de ensino e entrevistas com 17 professores que lecionavam no campo dos estudos organizacionais na pós-graduação stricto sensu, buscando recursos da pesquisa biográfica. Todavia, apesar das contribuições da tese, a autora sugere a realização de pesquisas com os estudantes para verificar como o campo dos EO estrutura sua aprendizagem ao longo dos cursos de pós-graduação e também a ampliação da pesquisa para cursos profissionais.

A partir desses exemplos percebe-se que o nível de pesquisa tem muitas possibilidades e que pode se relacionar com os outros, por exemplo, o trabalho de Waiandt (1999) trabalha no âmbito do campo dos estudos organizacionais, mas acaba analisando tanto o currículo de maneira geral como as formas de ensinar dos professores.

\subsection{A história das instituições educacionais}

Outro campo temático da historiografia da educação brasileira é a história das instituições educacionais e seu sistema, que suportam um arsenal de fontes e de informações fundamentadas para a formulação de interpretações sobre elas próprias e, sobretudo, sobre a história da educação brasileira. Essas instituições, por mais heterogêneas que sejam, "aparecem como localidades que não podem ser negligenciadas como amostra significativa do que acontece em termos educacionais em qualquer país e, especialmente, no Brasil, onde as análises governamentais têm a tendência de obscurecer a problemática de seu sistema escolar" (Gatti Jr., 2002:4).

A história das instituições educacionais integra uma tendência recente em historiografia, que confere relevância epistemológica e temática ao exame das singularidades sociais em detrimento das precipitadas análises de conjunto (macrossociológicas) que, sobretudo na área educacional, se faziam presentes. Nesse sentido, esse movimento historiográfico enfatiza pesquisas locais, menos generalizantes, em que o sujeito, até então mero reflexo do grupo social a que pertencia, torna-se o ator da história.

Compreender a existência histórica de uma instituição escolar é sistematizar e escrever o itinerário de vida em sua multidimensionalidade, conferindo um sentido histórico. Magalhães (1998, apud Gatti Jr., 2009) elenca as categorias de análise mais utilizadas na pesquisa sobre a história das instituições educacionais: espaço (local/lugar, edifício, topografia); tempo (calendário, horário, agenda antropológica); currículo (conjunto das matérias lecionadas, métodos, tempos etc. ou racionalidades de prática); modelo pedagógico 
(construção de uma racionalidade complexa que articula a lógica estruturante interna com as categorias externas que a constituem — tempo, lugar e ação); professores (recrutamento, profissionalização, formação, organização, mobilização, história de vida, itinerários, expectativas, decisões, compensações); manuais escolares; público (cultura, forma de estimulação e resistências); dimensões (níveis de apropriação, transferências da cultura escolar, escolarização, alfabetização, destinos de vida).

As categorias relativas ao estudo das instituições escolares perpassam por todos os níveis anteriores propostos. Assim, este nível almeja dar conta dos vários sujeitos envolvidos no processo educativo,

investigando o que se passa no interior das escolas, gerando um conhecimento mais aprofundado desses espaços sociais destinados aos processos de ensino e de aprendizagem, por meio da busca da apreensão daqueles elementos que conferem identidade à instituição educacional, ou seja, daquilo que lhe confere um sentido único no cenário social do qual fez ou ainda faz parte, mesmo que ela tenha se transformado no decorrer dos tempos (Gatti Jr., 2002, 2009:252).

Além dessas categorias, Nosella e Buffa (2005), tomando o conceito de trabalho como categoria fundamental, propõem o exame dos seguintes aspectos: origem, criação, construção e instalação; prédio (projeto, implantação, estilo e organização do espaço); mestres e funcionários (perfil); clientela (alunos e ex-alunos); saber (conteúdos escolares), evolução e vida (cultura escolar, prédio, alunos, professores e administradores, normas). Vinculando as categorias, os autores ressaltam a organização e a vida econômica, política e cultural da cidade e, sobretudo, o destino profissional dos alunos, pois "[...] é essencial tanto indagar a origem social e o destino profissional dos atores de uma instituição escolar para se definir seu sentido social, quanto analisar os currículos utilizados para compreender seus objetos sociais" (Nosella e Buffa, 2005:365).

Para os autores, o trabalho influi nos processos educativos dos homens e na configuração das instituições escolares. A relação escola-trabalho não se reduz, porém, nem à preparação profissional, nem à imediata qualificação de mão de obra, pois existe uma complexa integração histórica entre o mundo do trabalho e a escola, sem que cada um perca suas especificidades e sua autonomia, o que pode significar, por exemplo, que a distinção social e não o trabalho se torna o princípio educativo em algumas instituições escolares (Buffa e Nosella, 1996 apud Gatti Jr., 2009).

Dessa maneira, os estudos têm seguido um roteiro de pesquisa em que se destacam 
preocupações com os processos de criação e do desenvolvimento das instituições educativas, a configuração e as mudanças ocorridas na arquitetura do prédio escolar, os processos de conservação e mudança do perfil dos alunos, os destinos profissionais e pessoais dos alunos, as formas de configuração e formação do saber veiculado nessas instituições de ensino etc. (Gatti Jr., 2009:254)

Na área de administração, desde a década de 1970, se percebe, mesmo que de forma tímida, a preocupação de pesquisadores em se registrar a contribuição de diferentes instituições relacionadas com a trajetória da administração, como, por exemplo, Matta (1979), Martins (1990) e Fachin (2006).

Matta (1979) escreveu a história da Escola de Administração da UFBA, narrando os desafios para consolidar o curso em Salvador. Segundo o autor, as atividades da Escola de Administração da UFBA começaram em 1959, quando o reitor Edgar Santos trouxe à Bahia missões norte-americanas da Graduate School of Business Administration (MSU) e da Schoool of Public Administration (USC), para selecionar candidatos à bolsa no exterior. Mesmo em uma sede improvisada, Edgar Santos designou o professor Oldegar Franco Vieira para dirigir o programa e, em 14 de setembro de 1959, convocou os candidatos aos primeiros exames vestibulares para admissão aos cursos de graduação - bacharelado em Administração de Empresas e Administração Pública. Os estudantes aprovados cursariam, inicialmente, as disciplinas de um tronco comum - espécie de ciclo básico — , até que os "mestres" de disciplinas profissionalizantes retornassem, a partir de 1962, de suas bolsas de estudo no exterior (Matta, 1979). As aulas iniciaram em 1960, numa sala do subsolo do prédio - "palácio" - da reitoria, no Canela. Nesse mesmo ano, os candidatos ao mestrado dos EUA viajaram para sua qualificação. Nos dois primeiros anos do curso de administração, os estudantes tiveram aulas de matemática, estatística, geografia econômica, economia, sociologia, ciência política, direito público e privado, legislação trabalhista, contabilidade, inglês e comunicações (Matta, 1979). Em 1961, retornam os primeiros professores bolsistas dos EUA, quando Laffayete Pondé é nomeado para dirigir a Escola de Administração e a instituição passará por sucessivas fases de afirmação institucional, no âmbito da universidade. Em 1962, a EA/UFBA passa a figurar no Estatuto da Universidade e, em 1964, é aprovado seu regimento interno. Essa história ressalta o caráter empreendedor do reitor Edgar Santos; todavia, também, trouxe uma série de desafios para a consolidação do curso nos primeiros anos. Este trabalho é rico em detalhes e contextualiza a fundação da Escola de Administração no contexto social e político brasileiro.

Martins (1990) desenvolveu um trabalho sobre a trajetória de escolas e cursos de administração pública no Brasil, analisando os currículos dos cursos, 


\section{Contribuições metodológicas da historiografia da educação à história do ensino de administração}

Atualmente, os estudos no campo historiográfico da educação, influenciados pela história nova, retratam a história de um passado não muito distante envolvendo histórias e relatos orais da vida dos professores e suas práticas de formação, as quais despontam como uma nova opção de pesquisa. Nesse sentido, destacam-se, por exemplo, a história oral, a biografia, a autobiografia e a história de vida.

Queiroz (1987) ressalta que os relatos orais são categorizados em depoimentos e histórias de vida. A história de vida se define como o relato de um narrador sobre sua existência através do tempo, tentando reconstituir os acontecimentos que vivenciou e transmitir a experiência que adquiriu; quem decide o que vai relatar é o narrador. Já nos depoimentos, a entrevista é direcionada pelo pesquisador, uma vez que ele busca obter apenas o essencial para sua pesquisa. Outros métodos de relatos orais são citados por Bragança e Maurício (2008), a biografia e a autobiografia. Uma narrativa autobiográfica equivale a um relato sobre a própria vida, enquanto uma biografia corresponde à escrita sobre a vida no geral.

A história oral se caracteriza pelo registro de narrativas com pessoas que podem fazer revelações sobre acontecimentos, conjunturas, instituições, modos de vida ou outros aspectos da história contemporânea. Através de relatos, sobretudo o oral, oportunizam conhecimentos que retratam as imagens, as memórias, os saberes e fazeres. Tais conhecimentos vêm carregados das identidades assumidas e das transformações que vão se colocando na vida pessoal e profissional. A metodologia de história oral engloba a caracterização e o estudo do indivíduo em sua singularidade, e o que antes era relegado ao passado começa assim a trilhar um novo campo da prática, a contemporaneidade.

Para a história oral, a narrativa constitui-se como a essência através da qual será narrada essa história, suas memórias ou seu depoimento de vida, não sendo o entrevistado o foco da pesquisa, mas sim a história que traz consigo, permitindo perceber as conexões sociais e as interfaces com o objeto de estudo; como reflete Nóvoa (2000:15), “essa profissão precisa de se dizer e de se contar: é uma maneira de compreendê-la em toda a sua complexidade humana e científica".

A história oral procura dar voz ao professor, evidenciando suas impressões, experiências, seu modo de ver o mundo e a profissão escolhida, tornando possível uma maior interação com a prática profissional e suas memórias. Através da perspectiva de fazer uma conexão com seu "eu" pessoal, torna-se 
possível identificar o perfil do professor e seu caminho escolhido, bem como seu legado de conhecimento. Segundo Nóvoa (2000:16), “A identidade não é um dado adquirido, não é uma propriedade, não é um produto". A identidade é um lugar de lutas e de conflitos, é um espaço de construção de maneiras de ser e de estar na profissão. Por isso, é mais adequado falar em processo identitário, realçando a mescla dinâmica que caracteriza a forma como cada um se sente e se diz professor. De acordo com o autor, nada está totalmente dissociado do ser, de sua história de vida, de seu percurso, de sua maneira de ser e reflete naturalmente em sua práxis educadora; o que caracteriza seu processo de identidade, estando este em constante fluxo de construção.

Ainda segundo Nóvoa (2000), a maneira de lecionar está intrinsecamente ligada ao que se é como pessoa. O autor reflete que a identidade do professor se tece com múltiplos fios, mas todos eles fazem parte da mesma teia da vida, ou seja, estão diretamente associados à maneira de ser, estar e entender o mundo. Além do mais, as abordagens orais refletem uma faceta multidisciplinar do conhecimento a ser compartilhado.

Segundo Meihy (1991:15), "[...] as técnicas de registro e análise da oralidade são mais do que a realização de entrevistas". Assim, as etapas sugeridas por Meihy devem ser respeitadas na pesquisa de história oral, como: 1) Pré-entrevista: explica-se o projeto e marca-se a entrevista; 2) Entrevista: registrada com a devida autorização do professor; 3) Transcrição da entrevista: passagem da oralidade para a escrita; 4) Textualização da entrevista: a narrativa é revisada e o texto pode ser melhorado; 5) Conferência: cada professor revê sua narrativa em forma de texto, fazendo as correções ou complementações necessárias; e, por último, 6) Análise: interpretação das narrativas, relacionando-as ao referencial teórico ligado aos estudos que vinculam a oralidade com a educação e, mais especificamente, com a vida ou carreira dos professores.

Segundo Nóvoa (2000:71),

As experiências de vida e os ambientes socioculturais são obviamente ingredientes-chave da pessoa que somos, do nosso sentido de eu. Conforme o quanto investigamos nosso "eu" no nosso ensino, na nossa experiência e no nosso ambiente sociocultural, assim concebemos a nossa prática. Nessa perspectiva pode-se imaginar a pesquisa oral como uma percepção do passado; como algo que tem continuidade hoje e cujo processo histórico não está acabado.

A história oral "garante sentido social à vida de docentes e leitores que passam a entender a sequência histórica e a sentirem-se parte do contexto 
em que vivem" (Meihy, 1996:10). Nesta direção, também Chartier (2002:84) dirige-se ao relato como singular na história, pelo fato de manter uma relação específica com a verdade, pois as construções narrativas pretendem ser "a reconstituição de um passado que existiu".

Thompson (1992:22) a conceitua como "uma prática social que promove mudanças que modificam tanto o conteúdo quanto a finalidade da história". Assim, para o autor, a história oral transforma o foco da própria história descortinando novos caminhos e novas agendas de pesquisa. Neste contexto, percebe-se que as vivências e as formas de viver do professor dentro e fora da escola, suas identidades e culturas ocultas têm impacto sobre os modelos de ensino e sobre a prática educativa (Goodson, 1992).

Outra metodologia abordada neste ensaio é a biografia ou autobiografia, que se caracteriza pela abordagem de várias fontes com o propósito de compreender a história e o trajeto de vida de uma pessoa. Podem ser utilizadas cartas, fotos, filmagens, documentos pessoais, depoimentos, entre outros recursos, que permitem ao pesquisador "sentir" a profundidade da história do sujeito. A autobiografia pode ser vista como o resgate do próprio indivíduo, pontuando os acontecimentos mais relevantes de sua vida na totalidade, como coloca oportunamente Lejeune (2003:37): “A autobiografia é a narração em prosa que uma pessoa real faz da sua própria vida, quando põe a tônica na sua vida individual e, em particular, na história da sua personalidade". Através da autobiografia, o mestre pode retratar suas experiências e vivências, favorecendo uma interação entre essa experiência e sua pessoa, podendo-se, assim, conceber uma reflexão sobre a (auto)formação e a formação de novos educadores. Desta maneira, percebe-se que a biografia e a autobiografia focam a trajetória individual, contudo em um processo coletivo de constituição (Bragança e Maurício, 2008).

As principais características da autobiografia são: 1) o discurso direcionado ao leitor, levando muitas vezes a uma não reflexão sobre o vivido; 2) a preocupação com a rememoração das experiências pessoais e sua articulação em um contexto histórico mais amplo, destacando uma preocupação com a sequência temporal; 3) o uso da descrição para revelar os momentos de sua história; 4) a intencionalidade. Como aponta Lacerda (2000:84), “[...] as lembranças aparecem como produtos de um testemunho ocular da história de seu tempo, como se cada escritor pudesse elaborar seu discurso de forma impermeável às contradições, às interpretações sociais e às subjetividades". Assim, a história de vida dialoga com as memórias individuais e coletivas, às quais ressurgem dos conceitos, valores e crenças presentes no passado. 
Bertaux (1997:34), nesse contexto, distingue claramente as diferenças entre autobiografia e biografia, sendo a autobiografia uma construção do indivíduo a partir de uma narrativa escrita e autorreflexiva, com destaque para a totalidade das memórias, ou seja, da história de vida. Já a biografia retrata um relato oral e é permeada pelo diálogo entre o pesquisador e o indivíduo a partir de uma espécie de filtro em que se priorizam fragmentos. Diferentemente, a história de vida do pesquisado passa pelo crivo do pesquisador, que pontua sob seu olhar o que é relevante ou não.

A descrição autobiográfica, ou o relato que revela a formação do indivíduo, cria uma ponte entre o passado e o presente, possibilitando um campo de busca e um entendimento de como se retrata o passado, o presente, e, singularmente, as memórias da escola e da formação (Bragança e Maurício, 2008:257). Perceber a relação entre as narrativas autobiográficas no processo de formação e autoformação é crucial para se entender a holística nos processos que constituem a aprendizagem do docente. As características pessoais e os vestígios encontrados nas marcas deixadas no percurso individual/coletivo, visíveis nas biografias e autobiografias, descortinam aprendizagens da formação e profissão. Ao identificar a prática de ensino como uma ação crítica e social, espera-se que o professor seja uma pessoa reflexiva, que procura respostas a partir de e sobre sua própria prática. A autorreflexão, o contato com os outros e as ações cotidianas possibilitam que o professor aprenda com seus erros e, sobretudo, sistematize a reflexão de seu autoconhecimento e de sua prática de ensino.

Josso (2004) ressalta que as experiências são vivências particulares. São aquelas que ganham status de significação quando são realizadas conforme um trabalho de reflexão sobre o que se passou, sobre o que foi observado e trabalhado numa perspectiva de reflexão, sendo percebidas e sentidas. As experiências ajudam a formar as identidades e subjetividade e constituem "um referencial que nos ajuda a avaliar uma situação, uma atividade, um acontecimento novo" (Josso, 2004:49). Torna-se importante, assim, saber separar tais experiências e introduzir níveis coerentes e lógicos entre elas mesmas, do prisma de uma história de vida que permite entender os diversos fragmentos da formação de um professor. Quando se faz a construção das experiências e das vivências, sincronicamente, há um aumento de tomada de consciência, de mudança, de criatividade, de responsabilidade, de interação, dos aspectos indispensáveis nos processos de aprendizagem, do conhecimento e da formação docente.

A abordagem metodológica da história de vida não significa um fim, mas propicia o entendimento dos fatos e dos momentos em um dado contexto 
social. É um método que tem como principal característica, justamente, a preocupação com o vínculo entre pesquisador e sujeito.

Haguette (1992) entende que a metodologia de história de vida, dentro da abordagem biográfica, relaciona duas perspectivas metodológicas ligadas uma à outra, podendo ser utilizadas como documento ou como técnica de coleta de dados. Acrescenta-se, nas duas perspectivas, a produção de sentido — importante proposta da aplicação deste método. A utilização da história de vida como abordagem metodológica vem evoluindo continuamente. Foi introduzida no meio acadêmico em 1920, pela Escola de Chicago, e desenvolvida por Znaniescki, na Polônia. A partir da década de 1960, esse método de pesquisa procurou estabelecer as estratégias de análise do vivido, constituindose num método de coleta de dados do homem, no contexto de suas relações sociais. São características do método história de vida: 1) Preocupação com o vínculo entre pesquisador e pesquisado; 2) Há uma produção de sentido tanto para o pesquisador quanto para o sujeito: "saber em participação"; 3) História contada da maneira própria do sujeito; 4) ligação entre o individual e o social. A narrativa história de vida apresenta um foco temporal e expressivo, por meio, essencialmente, do relato como fonte de descoberta histórica (Bragança e Maurício, 2008:257). Ainda segundo os autores, as histórias de vida apresentam sempre a participação de atores, que trazem sentidos e vida para a narrativa; há também os personagens que se identificam como autores que se colocam na condição de atores, como é o caso da autobiografia, ou ainda os personagens externos, que são responsáveis pela transcrição do relato, sendo o caso das biografias.

Resumindo, o trabalho com relatos e histórias de vida faz emergir discussões sobre temas e questões que despertam dúvidas, vislumbrando também as dimensões da vivência social e da história pessoal. A pesquisa por meio da história de vida não é uma pesquisa somente no passado; ela também é diacrônica, podendo ser relacionada com o presente, e, assim, necessita estar elencada num conjunto de significações que fazem parte da vida cotidiana. A abordagem dessa história faz com que sejam revistos e sentidos, no meio acadêmico, aspectos que num primeiro momento parecem não ter importância, como o carinho e a aproximação com o outro. A pesquisa científica que aborda, por exemplo, a história de vida, a memória, o diário biográfico e a narrativa de formações traz para si uma profunda reflexão e igualmente certa subjetividade, já que ressalta a importância de se ouvir a voz do professor e, assim, entender e perceber o que está por trás da pessoa dando sentido à sua formação através de suas experiências, as quais possibilitam a percepção de que o "eu pessoal" está holisticamente ligado ao "eu profissional", e que os 
dois aprendem a partir de sua história de vida. O quadro 2 resume as principais contribuições metodológicas.

Quadro 2

Contribuições metodológicas da historiografia da educação

\begin{tabular}{|c|c|}
\hline $\begin{array}{l}\text { Gênero } \\
\text { Metodológico }\end{array}$ & Descrição \\
\hline Biografia & $\begin{array}{l}\text { Abordagem de várias fontes com o propósito de compreender a história e o trajeto } \\
\text { de vida de uma pessoa. É realizada por um pesquisador diferente do indivíduo } \\
\text { pesquisado. Permeia a própria existência do indivíduo. Diferentemente, a história de } \\
\text { vida do pesquisado passa pelo crivo do pesquisador, que pontua sob seu olhar o que } \\
\text { é relevante ou não. }\end{array}$ \\
\hline Autobiografia & $\begin{array}{l}\text { Resgate do próprio indivíduo, pontuando os acontecimentos mais relevantes de sua } \\
\text { vida na totalidade. Retrata as experiências e vivências, favorecendo uma reflexão sobre } \\
\text { a (auto) formação e a formação de novos educadores. }\end{array}$ \\
\hline $\begin{array}{l}\text { História de } \\
\text { vida }\end{array}$ & $\begin{array}{l}\text { Relato de um narrador sobre sua existência através do tempo, tentando reconstituir os } \\
\text { acontecimentos que vivenciou e transmitir a experiência que adquiriu. Quem decide } \\
\text { o que vai relatar é o narrador. Existe a intermediação do pesquisador, que o ajuda a } \\
\text { construir a própria história. }\end{array}$ \\
\hline História oral & $\begin{array}{l}\text { Registro de narrativas com pessoas que podem fazer revelações sobre } \\
\text { acontecimentos, conjunturas, instituições, modos de vida ou outros aspectos da } \\
\text { história contemporânea. }\end{array}$ \\
\hline $\begin{array}{l}\text { Análise de } \\
\text { depoimentos }\end{array}$ & $\begin{array}{l}\text { A pesquisa é direcionada pelo pesquisador, uma vez que ele busca obter apenas o } \\
\text { essencial para sua pesquisa. }\end{array}$ \\
\hline
\end{tabular}

Fonte: Elaboração própria.

\section{Considerações finais}

A proposta de uma agenda de pesquisas tendo por foco a história do ensino de administração deve considerar dimensões: a) a constituição de uma área temática de pesquisas enquanto construto teórico e metodológico; b) a construção de uma comunidade de interesses, saberes e práticas de pesquisadores; c) a definição de temas agregadores que serão, propriamente, a agenda; d) a institucionalização da área temática junto aos públicos e instituições interessadas, como associações científicas e organismos reguladores e financiadores; e e) a integração da produção do subcampo nas disciplinas escolares.

Estas dimensões da agenda não ocorrem isoladamente, mas estão imbricadas de modo interdependente. Discorrendo sobre cada dimensão, pode-se considerar: 
a) A história do ensino de administração é uma convergência teórico-metodológica de história, de história da educação e de história da administração. $\mathrm{O}$ encontro das três disciplinas resulta em um recorte interdisciplinar. Como ocorreu na área de educação ao incorporar a história, a administração deve apropriar-se de sua história adotando uma postura crítica e reflexiva, fazendo valer as construções e os experimentos destes outros campos, para garantir qualidade;

b) Uma comunidade de interesses e práticas forma-se por afinidades e pautas de interesses comuns, compartilhamento de projetos e, especialmente, pela construção de um éthos identitário, o que requer liderança, adesão e compromisso. Se existem intenções de fortalecer uma talvez nascente comunidade de interesses, líderes das linhas de pesquisas institucionais devem estabelecer pactos entre projetos e instituições, promover encontros e produção coletiva;

c) Os temas agregadores referem-se à trajetória de administração enquanto campo; à história das instituições de ensino e do sistema de instituições de apoio e regulação no que diz respeito às influências exercidas sobre o ensino e a pesquisa; à história dos legados de ensino (currículos, programas, experiências vividas, materiais, a vida dos mestres referenciais, suas trajetórias e impactos). Há, portanto, um vasto campo de interesses comportando metodologias plurais e critérios adequados de escolha, uso e avaliação da própria qualidade de pesquisa.

d) A institucionalização da temática deve partir, precisamente, da percepção de sua relevância e efetiva qualidade. Assim como as comunidades de história e de história da educação organizaram grupos temáticos para o estudo da história da educação, os pesquisadores de administração podem se organizar entre seus pares e de forma multidisciplinar com historiadores e educadores, o que pode resultar em redes para pesquisas conjuntas, coorientação de teses e dissertações e, especialmente, publicações interdisciplinares qualificadas. A organização de eventos específicos e a inserção em revistas qualificadas na área de administração e nas áreas conexas, bem como a participação em eventos regionais e nacionais das sociedades científicas de administração, educação e história, darão visibilidade e organicidade ao campo.

e) É necessário integrar os produtos das investigações do subcampo de história do ensino de administração aos programas de ensino das disciplinas escolares, pois a qualidade da formação das novas gerações depende de um ensino atualizado que incorpore, o máximo possível, os novos conhecimen- 
tos produzidos pela via da investigação científica. Por outro lado, o próprio desenvolvimento de cada área científica depende da preparação de novos quadros de pesquisadores, o que não pode ser alcançado sem o desenvolvimento quantitativo e o aprimoramento qualitativo do ensino do respectivo subcampo.

Finaliza-se com a proposta de se ensinar a história do ensino de administração no Brasil, disciplina que é praticamente inexistente em nossos currículos de graduação e pós-graduação, mais particularmente, a história do ensino de administração, que pode ser um componente curricular (matéria de ensino) de disciplinas e atividades que se propõem a formar mestres e doutores.

Para concluir, faz-se uma citação de Beatriz Sarlo (2007), que lembra que "o passado é sempre conflituoso", portanto, deve ser abordado com cautela. A própria autora completa: "Além de toda a decisão pública ou privada, além da justiça e da responsabilidade, há algo inabordável no passado [...] o retorno do passado nem sempre é um momento libertador da lembrança, mas um advento, uma captura do presente" (Sarlo, 2007:9).

\section{Referências}

BERTAUX, D. Les récits de vie. Paris: Nathan, 1997.

BITTENCOURT, C.M.F. Disciplinas escolares: história e pesquisa. In: OLIVEIRA, M.A.T.; RANZI, S.M.F. (Org.) História das disciplinas escolares no Brasil: contribuições para o debate. Bragança Paulista: Edusf, 2003.

BRAGANÇA, I.F.S.; MAURÍCIO, L.V. Histórias de vida e práticas de formação. Natal: EDUFRN; São Paulo: Paulus, 2008.

BURKE, P. A escola dos Annales (1929-1989): a revolução francesa da historiografia. São Paulo: Editora da Unesp, 1997.

CHARTIER, R. A história cultural: entre práticas e representações. 2. ed. São Paulo: Martins Fontes, 2002.

CHERVEL, A. História das disciplinas escolares: reflexões sobre um campo de pesquisa. Teoria \& Educação, v. 2, 1990.

CNPq. Tabela de áreas do conhecimento. Disponível em: <www.cnpq.br/areas/tab conhecimento/index.htm>. Acesso em: 5 mar. 2010.

COELHO, F. Educação superior, formação de administradores e setor público: um estudo sobre o ensino de administração pública — em nível de graduação — no 
Brasil. Tese (doutorado em administração pública e governo) — Fundação Getulio Vargas, São Paulo, 2006.

COELHO, F.S.; NICOLINI, A.M. Uma contribuição à história do ensino de graduação em administração pública no Brasil (1952 1994): proposta de periodização e análise de um dos estágios de construção. In: ENCONTRO DA ANPAD, XXXIV, Rio de Janeiro, 2010. Anais...

COSTA, A.M.; BARROS, D.F.; MARTINS, P.E.M. Perspectiva histórica em administração: panorama da literatura, limites e possibilidades. In: ENCONTRO DA ANPAD, XXXIII, São Paulo, 2009. Anais...

COVRE, M.L.M. A formação e a ideologia do administrador de empresas. Rio de Janeiro: Vozes, 1981.

CURADO, I.B. O desenvolvimento dos saberes administrativos em São Paulo: Uma análise histórica. Tese (doutorado em administração) — Fundação Getulio Vargas, São Paulo, 2001a.

CURADO, I. Pesquisa historiográfica em administração: uma proposta mercadológica. In: ENANPAD, Campinas, 2001b. Anais...

DECCA, E.S. Questões teórico-metodológicas da história. In: SAVIANI, Demerval; LOMBARDI, José Claudinei; SANFELICE, José Luis (Org.). História e história da educação. Campinas: Autores Associados, 1998.

FACHIN, R.C. Construindo uma associação científica: trinta anos da Anpad - memórias, registros, desafios. Porto Alegre: s.n., 2006.

FERREIRA, M.M. CPDOC: 30 anos. Rio de Janeiro: Editora FGV, 2003.

FISCHER, T. A perduração de um mestre e uma agenda de pesquisa na educação de administração: artesanato de si, memória dos outros e legados de ensino. Revista Organizações \& Sociedade, Salvador, v. 17, n. 52, p. 209-219, jan./mar. 2010.

FISCHER, T.A. O ensino de administração pública no Brasil. Tese (doutorado em administração) — Universidade Federal de São Paulo, São Paulo, 1984.

GATTI JR., D. A história das instituições educacionais: inovações paradigmáticas e temáticas. In: ARAÚJO, J.C.; GATTI JR., D. (Org.). Novos temas em história da educação brasileira: instituições escolares e educação na imprensa. Campinas: Autores Associados; Uberlândia: Edufu, 2002. p. 3-24.

GATTI JR., D. A história e a historiografia das instituições escolares. In.: LOMBARDI, J.C.; SAVIANI, J.C. (Org.). Navegando pela história da educação brasileira: 20 anos de HISTEDBR. Campinas: Autores Associados/HISTEDBR, 2009. p. 240-258. 
GODOY, A.S.; MOREIRA, D.A.; TAKEI, A.T. Análise dos planos de ensino das disciplinas ligadas às teorias da administração nos cursos superiores de administração de empresas no município de São Paulo. In: ENCONTRO DA ANPAD, 2002. Anais...

GOODSON, I.F. Currículo: teoria e história. Petrópolis: Vozes, 1995.

GOODSON, I.F. Dar voz ao professor: as histórias de vida dos professores e o seu desenvolvimento profissional. In: NÓVOA, A. (Org.). Vidas de professores. Portugal: Porto, 1992. p. 63-78.

HAGUETEE, T.M.F. Metodologias qualitativas na sociologia. 3. ed. Petrópolis: Vozes, 1992.

JOSSO, M.C. Experiências de vida e formação. São Paulo: Cortez, 2004.

KEINERT, R.C. Perspectivas atuais do ensino de administração na Europa. RAE - Revista de Administração de Empresas, Rio de Janeiro, v. 26, n. 2, p. 65-70, abr./jun. 1986.

KEINERT, T.M.M. Os paradigmas da administração pública (1900-92). RAE - Revista de Administração de Empresas, v. 34, n. 3, p. 41-48, maio/jun. 1994.

LACERDA, L.M. Lendo vidas: a memória como escritura autobiográfica. In: CUNHA, M.T.S.; BASTOS, M.H.C.; MIGNOT, A.C.V. (Org.). Refúgios do eu: educação, história e escrita autobiográfica. Florianópolis: Ed. Mulheres, 2000. p. 81-107.

Le GOFF, J. A história nova. 2. ed. São Paulo: Martins Fontes, 1993.

LEJEUNE, P. Definir autobiografia. In: MOURÃO, P. (Org.). Autobiografia, autorrepresentação. Lisboa: Colibri, 2003.

LOBARDI, J.C. História e historiografia da educação. In.: LOMBARDI, J.C.; NASCIMENTO, M.I.M. (Org.). Fontes, história e historiografia da educação. Campinas: Autores Associados/HISTEDBR, 2004.

MARTINS, C.B. Surgimento e expansão dos cursos de administração no Brasil (1952-1983). Ciência e Cultura, São Paulo, v. 41, n. 7, p. 663-676, jul. 1989.

MARTINS, P.E.M. Escola Brasileira de Administração Pública: o Brasil versus a Universidade. Rio de Janeiro: Ebape, 1990.

MATTA, J.E. Escola de Administração: vinte anos de história institucional (19591979). Bahia: UFBA, 1979.

MEIHY, J.C.S.B. Canto de morte kaiowá: história oral de vida. São Paulo: Loyola, 1991.

MEIHY, J.C.S.B. Manual de história oral. São Paulo: Loyola, 1996. 
MORAIS, C.C.; PORTES, E.A.; ARRUDA, M.A. A história da educação: ensino e pesquisa. Belo Horizonte: Autêntica, 2006.

MOTTA, F.P. A questão da formação do administrador. RAE - Revista de Administração de Empresas, Rio de janeiro, v. 23, n. 4, p. 53-55, out./dez. 1983.

NICOLINI, A.M. Aprender a governar: a aprendizagem dos dirigentes públicos para as carreiras de Estado. Tese (doutorado em administração) — Universidade Federal da Bahia, Salvador, 2007.

NICOLINI, A.M. O futuro administrador pela lente das novas diretrizes curriculares: cabeças bem-feitas ou bem cheias? In: ENCONTRO DA ANPAD, XXVI, Salvador, 2002. Anais...

NOSELLA, P.; BUFFA, E. As pesquisas sobre instituições escolares: o método dialético marxista de investigação. Eccos: Revista Científica, v. 7, p. 351-368, 2005.

NÓVOA, A. (Org.). Vidas de professores. 2. ed. Portugal: Porto, 2000.

NÓVOA, A. (Org.). Os professores e a sua formação. Lisboa: Dom Quixote, 1992.

OLIVEIRA, F.B. Os cursos de pós-graduação lato sensu: gênese e evolução. In: ENCONTRO DA ANPAD, XVII, Salvador, 1993. Anais...

PESSANHA, E.C.; DANIEL, M.E.B.; MENEGAZZO, M.A. Da história das disciplinas escolares à história da cultura escolar: uma trajetória de pesquisa. Revista Brasileira de Educação, Rio de Janeiro, v. 27, p. 25-46, 2004.

PIERANTI, O.P. A metodologia historiográfica na pesquisa em administração: uma discussão acerca dos princípios e de sua aplicabilidade no Brasil Contemporâneo. Cadernos Ebape, v. VI, n. 1, mar. 2008.

QUEIROZ, M.I.P. Relatos orais: do "indivisível" ao "divisível”. Ciência e Cultura, São Paulo, v. 39, n. 3, p. 272-286, mar. 1987.

ROCHA, G.O.R. A pesquisa sobre currículo no Brasil e história das disciplinas escolares. In: GONÇALVES, L.A. (Org.). Currículo e políticas públicas. São Paulo: Autêntica, 2003. p. 41-61.

SARLO, B. Tempo passado: cultivo da memória e guinada subjetiva. Belo Horizonte: UFMG; São Paulo: Cia. da Letras, 2007.

SAUERBRONN, F.F.; FARIA, A. A utilização do método histórico em pesquisa acadêmica de marketing. In: ENCONTRO DE MARKETING DA ANPAD, Rio de Janeiro, 2006.

SAVIANI, D. Os balanços na historiografia da educação brasileira: sentidos e perspectivas. In: NEPOMUCENO, M.A.; TIBALLI, E.F.A. (Org.). A educação e seus sujeitos na história. Belo Horizonte: ARGVMENTVM, 2007. p. 163-180. 
SAVIANI, D.; LOMBARDI, J.C.; SANFELICE, J.L. História e história da educação. 3. ed. Campinas: Autores Associados/HISTEDBR, 2006.

SILVA, M.R. Ensino de administração: um estudo da trajetória curricular de cursos de graduação em Salvador. Dissertação (mestrado em administração) — Universidade Federal da Bahia, Bahia, 2007.

SILVA, M.R.; TEIXEIRA, L.; MAGALHÃES, O. O ensino de uma "outra gestão": o caso da Escola de Administração da Universidade Federal da Bahia. In: ENCONTRO DA ANPAD, XXIX, Brasília, 2005. Anais...

SKORA, C.M.; MENDES, D. As coisas novas: por que a TGA parou no tempo? In: ENANPAD, XXV, Campinas, 2001. Anais...

THOMSON, A.; FRISCH, M.; HAMILTON, P. Os debates sobre memória e história: alguns aspectos internacionais. In: AMADO, J.; FERREIRA, M.M. (Org.). Usos e abusos da história oral. Rio de Janeiro: Editora FGV, 2002. p. 65-92.

THOMPSON, P. A voz do passado: história oral. Tradução de Lólio Lourenço de Oliveira. Rio de Janeiro: Paz e Terra, 1992.

VERGARA, S.C. Projetos e relatórios de pesquisa em administração. São Paulo: Atlas, 1997.

VIZEU, F. Em algum lugar do passado: contribuições da pesquisa histórica para os estudos organizacionais brasileiros. In: ENCONTRO DA ANPAD, XXXI, Rio de Janeiro, 2007. Anais...

WAIANDT, C.A. O ensino dos estudos organizacionais nos cursos de pós-graduação stricto sensu em administração. Tese (doutorado em administração) — Universidade Federal da Bahia, Salvador, 2009. 